
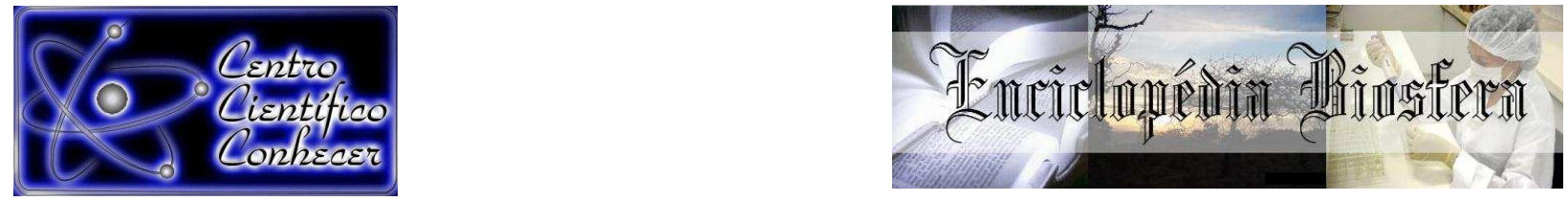

\title{
MODIFICAÇÕES NA PAISAGEM DECORRENTES DA CONSTRUÇÃO DA USINA HIDRELÉTRICA SÃO JOSÉ, REGIÃO NOROESTE DO RIO GRANDE DO SUL
}

Maureen de Moraes Stefanello1; Liane de Souza Weber²; Roselene Marostega Felker $^{3}$; Eliara Marin Piazza ${ }^{4}$ Paulo Henrique Jung ${ }^{5}$

${ }^{1}$ Eng. Florestal. Mestranda do PPG em Engenharia Agrícola - UFSM mmstefanello@gmail.com

${ }^{2}$ Eng. Florestal. Drª ${ }^{\text {. Prof. }}{ }^{\text {a }}$ Titular Depto. de Engenharia Florestal - UFSM

${ }^{3}$ Eng. Florestal. Doutoranda do PPG em Engenharia Florestal - UFSM

${ }^{4}$ Eng. Florestal. Doutoranda do PPG em Engenharia Florestal - UFSM

${ }^{5}$ Eng. Florestal. Mestrando do PPG em Eng. Florestal - UFSM

Recebido em: 08/09/2015 - Aprovado em: 14/11/2015 - Publicado em: 01/12/2015 DOI: http://dx.doi.org/10.18677/Enciclopedia_Biosfera_2015_196

\begin{abstract}
A construção de uma hidrelétrica pode provocar grandes transformações na paisagem regional, num processo contrário ao movimento de sua formação original, com impactos negativos para a fauna e flora. A implantação é definida por prérequisitos, tais como vazão, topografia e fatores geológicos, no entanto, muitas vezes não se observa o estudo integral da paisagem que aponte alternativas para a preservação dos recursos naturais. A Usina Hidrelétrica São José, com potência instalada de $51 \mathrm{MW}$, foi construída sobre o leito do rio ljuí, afluente da margem direita, do rio Uruguai, localizada entre os municípios de Cerro Largo, Salvador das Missões, Roque Gonzales e Mato Queimado, região noroeste do estado do RS. A formação do lago e o início de funcionamento da hidrelétrica estabeleceram nova paisagem no entorno. Os resultados conduziram a uma análise temporal da transformação da paisagem na região, identificando e quantificando as áreas de preservação permanente (APP) antes da construção da hidrelétrica no ano de 2005, e pós o início de seu funcionamento no ano de 2014. Desse modo objetiva-se identificar as APP que foram suprimidas com a construção do reservatório, e, elaborar um mapa com a nova realidade do local, com as APP que ocupariam as margens do reservatório, segundo a Legislação do Novo Código Florestal Brasileiro.
\end{abstract}

PALAVRAS-CHAVE: Área de Preservação Permanente; Código Florestal Brasileiro; reservatório artificial 


\title{
CHANGES IN THE LANDSCAPE ARISING FROM DEPLOYMENT OF SÃO JOSÉ HYDROELETRIC PLANT, NORTWEST REGION OF RIO GRANDE DO SUL
}

\begin{abstract}
The construction of a hydroelectric causes some changes in the local landscape, in a reverse process to the movement of his formation with negative impacts to the environment. The deployment is define by requirements like, water availability, topography and geological factors, in the most part without a full study about the landscape what show alternatives to the natural resources preservation. The São José Hydroelectric Plant, with power of $51 \mathrm{MW}$, was been built over riverbed of ljuí River, a creek on right border of Uruguai River, located between the cities of Cerro Largo, Salvador das Missões, Roque Gonzales e Mato Queimado, in the region northwest of RS state. The formation of the lake and the start of operation of the Hydroelectric was formed a new landscape in the surroundings areas. The results have provided the temporal analysis on the transformations of the landscape, identifying and quantifying the permanent preservations areas, before the building of the Hydroplant in 2005, and after his energy generating start in the year of 2014 . With the objective to identify which permanent preservations areas was remove with the deployment of reservoir, and to develop a map with the new local reality, with the permanent preservations areas what occupy the reservoir borders, according the New Brazilian Forest Code
\end{abstract}

KEYWORDS: Permanent Preservation Area; Brazilian Forest Code; artificial reservoir

\section{INTRODUÇÃO}

A utilização crescente de energia pela sociedade atual é irreversível devido aos avanços tecnológicos. No Brasil, $75 \%$ da matriz energética brasileira é composta de energia elétrica proveniente de hidrelétricas. No entanto, a avaliação do significado socioambiental da construção de uma hidrelétrica envolve a difícil ponderação de usufruir dos benefícios proporcionados pela geração de energia elétrica e arcar com os impactos negativos decorrentes da implantação do empreendimento (MINISTÉRIO DO MEIO AMBIENTE, 2006). Diante disso, a implantação e operação dessas hidrelétricas pode trazer vários problemas ambientais e sociais, que extrapolam o local e a região onde estão localizados esses empreendimentos.

A transformação do complexo ecossistema de um ambiente lótico (rio) em lêntico (lago), de maneira brusca, desencadeia uma série de desequilíbrios ecológicos e sociais (COELHO, 2008). Assim, a avaliação do significado sócioambiental da construção de uma hidrelétrica, segundo BATISTA et. al, (2012), refere-se ao ponto de vista ambiental, quando os impactos negativos vão desde a perda de fragmentos florestais e matas ciliares, com diminuição da biodiversidade, até a perda de paisagens culturais e naturais, além do aumento de processos erosivos e poluentes.

As matas ciliares, também denominadas de Áreas de Preservação Permanente (APP), são áreas com florestas e demais formas de vegetação naturais situadas, dentre outras, ao longo dos rios ou qualquer curso d'água desde o seu nível mais alto em faixa marginal com largura mínima variável a qual será tanto maior quanto maior a largura do mesmo, segundo a Lei 12.651 (BRASIL, 2012). 
Assim, matas ciliares devem ser preservadas e quando ausentes, recuperadas (restituídas a uma condição não degradada, que pode ser diferente de sua condição original) ou restauradas (restituídas o mais próximo possível da sua condição original) (BRASIL, 2012).

Para HINKEL (2003) as formações presentes nas APP's, apresentam-se com grande variação em sua composição florística e estrutural, estando estas variações relacionadas às características intrínsecas da área como relevo local, mosaico edáfico (solo), largura da faixa ciliar e do curso d’água, flutuação do lençol freático e histórico de perturbações. Atuando como filtros naturais ou como zona tampão de entrada de nutrientes no rio originários de planícies aluviais, estabilizadora de margens e auxilia a recarga de aquíferos subterrâneos e como habitat de animais silvestres (SALAMENE et. al., 2011).

Antigamente, não existia no país, nenhum movimento expressivo voltado a preservação do meio ambiente e assim as construções de usinas hidrelétricas eram propostas à luz de uma "ideologia da modernização" sem que os setores responsáveis se preocupassem com as alterações e mudanças que viessem a ocorrer no ambiente natural (MMA, 2006). Dessa forma, no Brasil, a preocupação com os impactos ambientais ocasionados por grandes empreendimentos, teve início na década de 1970. A Lei $n^{\circ} 6.938 / 81$, que institui a Política Nacional de Meio Ambiente, define 0 meio ambiente no Artigo $3^{\circ}$ como sendo 0 "conjunto de condições, leis, influências e interações de ordem física, química e biológica que rege a vida em todas as suas formas". Essa mesma Lei atribui ao Conselho Nacional de Meio Ambiente (CONAMA) o estabelecimento de normas e critérios específicos para tal (BRASIL, 1981).

A Resolução, CONAMA (1986), n001/86 estabelece qu e o estudo prévio dos impactos ambientais (EIA) é o instrumento de controle e planejamento ambiental, obrigatório em qualquer decisão pública ou privada que possa causar dano ao meio ambiente. Complementarmente, o Relatório de impactos ambientais (RIMA) deve ser o reflexo das conclusões obtidas no EIA, contendo recomendações técnicas em linguagem acessível ao público, devendo, ainda, ser ilustrado por tabelas, mapas, quadros, gráficos ou outras técnicas de comunicação visual.

Segundo COELHO (2008), a rápida transformação espaço-temporal da paisagem de um empreendimento hidrelétrico, implica mudanças no uso e ocupação do solo, requer a utilização de dados de fontes confiáveis para o seu mapeamento e monitoramento. Nesse contexto, os dados de sensoriamento remoto, pelo caráter sinóptico e alta frequência de aquisição, são fontes confiáveis para satisfazer a essas necessidades. O mesmo autor refere-se à utilização dos dados relativos ao uso do solo tendo uma utilização mais precisa e ampla através dos sistemas de geoprocessamento. Esses sistemas de ferramentas computacionais são eficientes para a obtenção e tratamento dos dados, permitindo interrelacioná-los com outros fenômenos, além de avaliar a evolução espacial e temporal da paisagem (RODRIGUES et al., 2013).

Diante deste fato, as metodologias possíveis de serem reproduzidas por meio de ferramentas de SIG, tornam-se alternativas viáveis para a mensuração do impacto causado à paisagem, bem como, as análises referentes as APP existentes anteriormente à instalação de empreendimentos hidrelétricos e as que existem atualmente (XAVIER \& ZAIDAN, 2011). Os mesmos autores mencionam que as condições oferecidas por esses métodos permitem integrar informações cartográficas e topográficas, possibilitando por meio de análises ambientais, 
estabelecer correlações espaciais, relação causa-efeito e aspectos temporais, que antes eram impraticáveis pelos meios tradicionais, dessa forma, auxiliando de maneira prática a investigação do impacto ambiental sofrido pela paisagem após a inundação da área.

O trabalho aqui relatado, irá demonstrar com a utilização de mapas, uma análise temporal, baseada nas condições topográficas e de cobertura do solo da área de abrangência da Usina Hidrelétrica São José (UHE São José), antes do início das obras no ano de 2005 e posteriormente no ano de 2014. Objetivando a avaliação do impacto ambiental causado na paisagem da área de entorno do reservatório, destacando as áreas de APP existentes anteriormente à inundação, àquelas que existem atualmente e as áreas de APP a serem criadas no local conforme a Legislação do Novo Código Florestal Brasileiro.

\section{MATERIAL E MÉTODOS}

Á área de abrangência da UHE São José, situa-se na divisa entre os municípios de Cerro Largo, Salvador das Missões, Roque Gonzales e Mato Queimado, pertencentes à região noroeste do estado do Rio Grande do Sul. A obra foi construída sobre o leito do rio ljuí, afluente da margem direita do rio Uruguai. $A$ micro bacia do rio ljuí, possui a extensão de, aproximadamente, $10.000 \mathrm{~km}^{2}$, e pertence a bacia do Uruguai, estando compreendida pelo quadrante de coordenadas geográficas -2847’01.60" S, -5447'31.84" O e -28 13'16.09” S, -54ㄴ1'37.38” O. Pertencente à tipologia florestal conhecida como Floresta Estacional Decidual, feição característica do Bioma Mata Atlântica (IBGE, 2012).

Os municípios localizam-se entre a região geomorfológica Planalto das Missões, onde as formas do relevo são homogêneas de modo geral, com colinas suaves, bem arredondadas, a maioria esculpidas em rochas vulcânicas básicas e poucas em rochas sedimentares e a altitude variando entre 50 e 200 m, cujas cotas decrescem em direção ao rio Uruguai. Apresenta solos profundos, com predomínio de Latossolos e Argissolos (IBGE, 2010). O clima é do tipo "Cfa", segundo classificação de Köppen, subtropical úmido, sem estação seca, com temperatura média anual de $22^{\circ} \mathrm{C}$, com precipitação média anual variando entre 1300 a 1800 $\mathrm{mm} / \mathrm{ano}$, com maiores valores em maio e junho (ALVARES et al., 2013).

A base de dados para este estudo foi extraída das imagens do Google Earth, que foram georreferenciadas e processadas pelo software ArcGis. Inicialmente, foi localizada nesta base de dados, os pontos referentes a micro bacia do rio ljuí, e também, a localização dos limites de abrangência do reservatório da barragem. A partir da localização da hidrelétrica no mapa, as imagens do ano de 2005 e 2014 foram georreferenciadas. Após, foram demarcados os limites topográficos de abrangência do reservatório. Uma vez delimitado o espelho d'água, foi possível delimitar as APP existente nas margens do reservatório. O mesmo procedimento foi realizado nas imagens do ano de 2005. Com base nas ferramentas do Software, foi possível quantificar as áreas suprimidas e o impacto ambiental que a paisagem sofreu após a construção da obra, e também, elaborar mapas comparativos do ano de 2005 e 2014, baseando-se nas áreas de APP. 


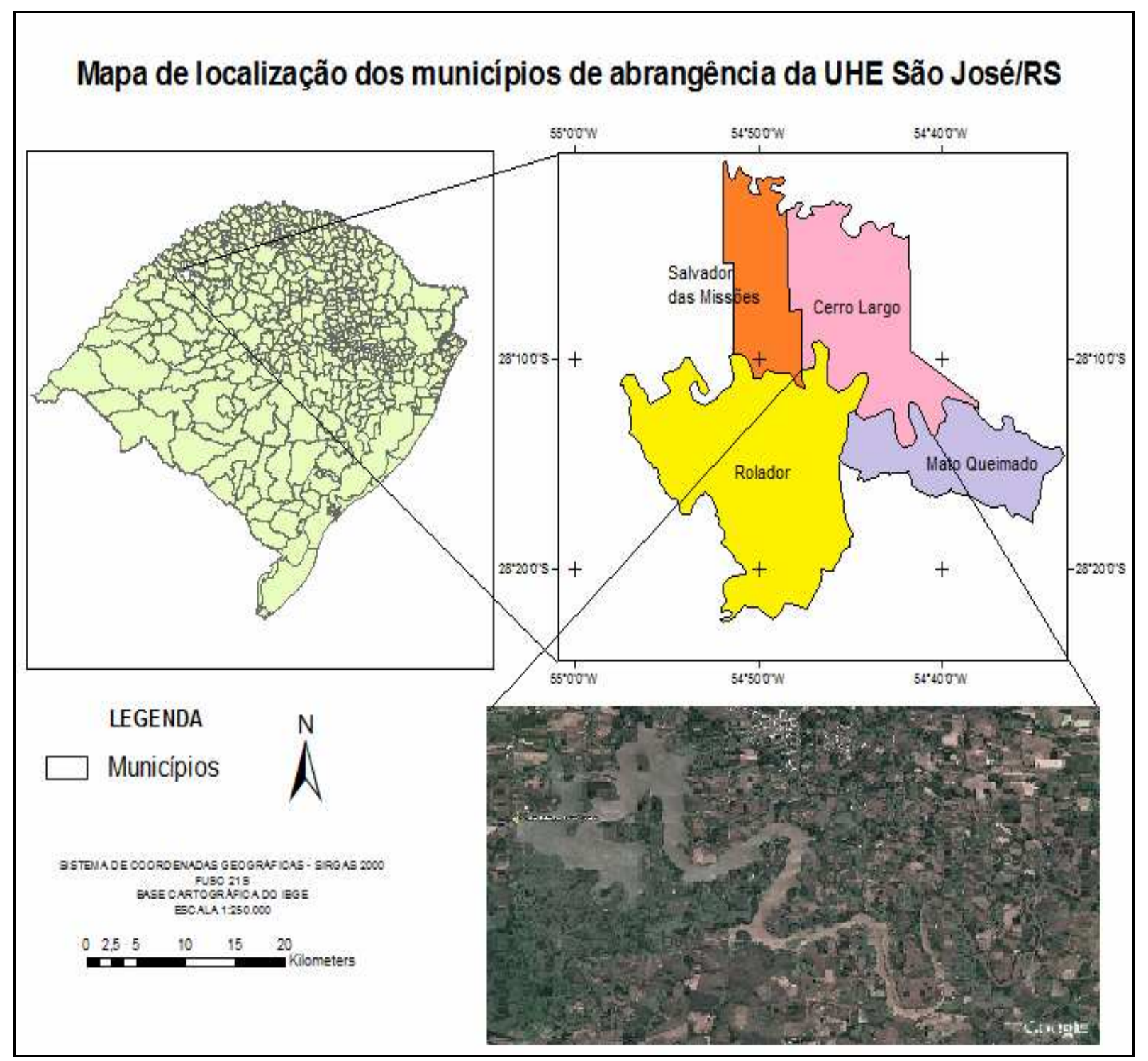

FIGURA 1: Mapa dos municípios de abrangência da UHE São José. Fonte: Autores

\section{RESULTADOS E DISCUSSÃO}

Pode-se observar na Figura 2, a porção do rio ljuí e as áreas de mata ciliar existentes no local, no ano de 2005, antes do início da construção da UHE São José, em que ambas as margens do rio ljuí encontravam-se, em boa parte, recobertas por vegetação de mata nativa, estas nas quais, exerciam a função de APP. 


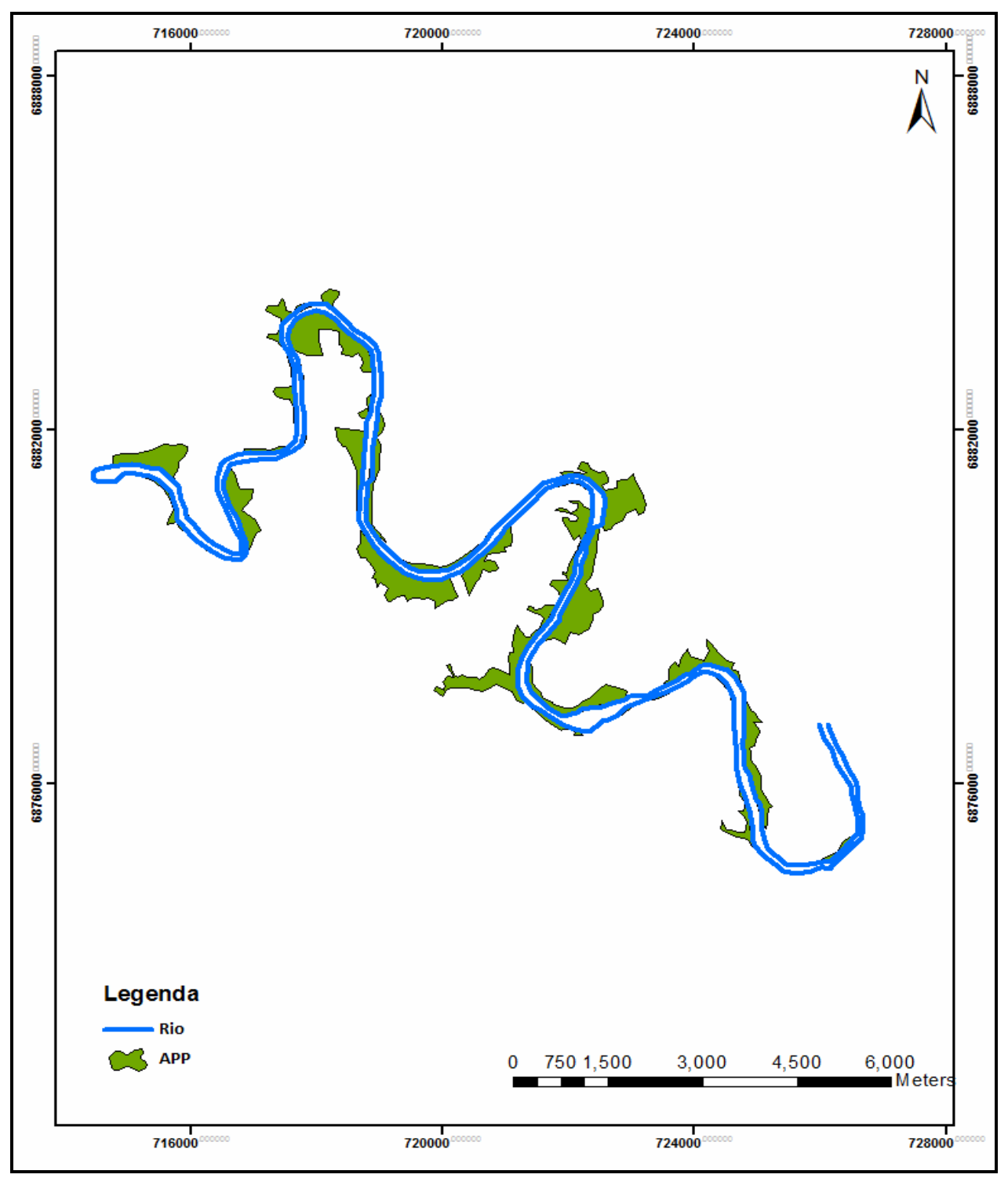

FIGURA 2: Mapa do leito do rio ljuí, com as APP no ano de 2005.

Fonte: Autores

Com a elaboração deste mapa, foi possível quantificar as áreas de APP que existiam na época, nas margens do rio ljuí, recobrindo uma área de aproximadamente 646,06 ha. Observa-se também, a largura que o rio ljuí possuía, de aproximadamente 110 metros na porção mais à direita e chegando a 165 metros na porção mais à esquerda. Além disso, podemos notar que em alguns trechos as margens do rio ljuí encontravam-se sem vegetação ciliar, estando, na época, ocupadas por áreas de lavouras, destinadas ao cultivo de soja e milho, campo nativo e pastagens para a criação de rebanhos. Além do mais, com o mapeamento do local, tornou-se possível visualizar as áreas que foram suprimidas com a formação do lago da UHE São José, dado relevante para a mensuração do impacto sobre a paisagem da localidade.

BATISTA et al. (2012) menciona que entre os problemas de cunho ambiental, a modificação da paisagem é o mais avassalador, de tal maneira que as próprias instalações das usinas e do reservatório, das linhas de transmissão de energia, do 
acúmulo e o inadequado manejo de resíduos sólidos e líquidos, da alteração das características físicas, químicas e biológicas das águas e o desmatamento, são algumas das modificações visivelmente perceptíveis e impactantes.

COELHO (2008) argumenta que os danos causados com a construção de uma usina, vão além dos danos ambientais, causando danos também na esfera social e econômica e para a população do entorno, pois interfere diretamente na biologia aquática e terrestre, na riqueza cultural e histórica do local.

Dessa forma, com a elaboração dos mapas no ano de 2014, foi possível quantificar as áreas que foram inundadas, após a formação do lago da usina, além de, visualizar as mudanças que a paisagem do local sofreu, uma vez que as áreas atingidas pelo alagamento, chegaram a cerca de 2.648 ha, como pode ser observado na Figura 3.

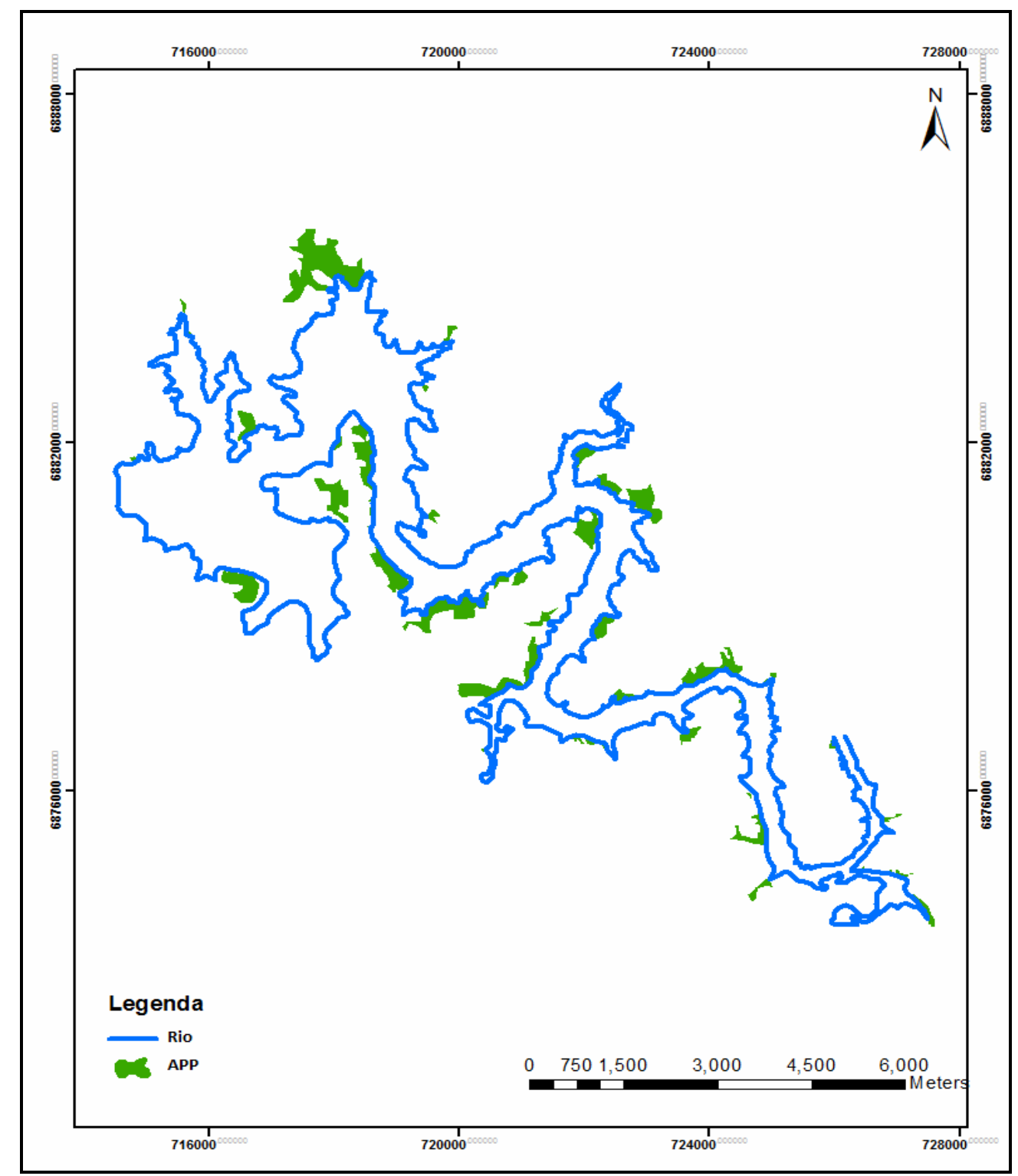

FIGURA 3: Mapa da área do lago da UHE São José com as áreas de Fonte: Autores. mata nativa no ano de 2014. 
Além disso, foi possível identificação das áreas que foram suprimidas após a inundação e as áreas de mata nativa que restaram nas margens da barragem da UHE São José. Ao mesmo tempo que, o local ocupado agora pelo lago da usina, acarretou na desocupação de 441 famílias que residiam na área, 1.994 pessoas e 421 propriedades, conforme dados do Estudos e Relatórios de Impactos Ambientais (EIA-RIMA).

Com a análise temporal foi possível verificar 0 alagamento de aproximadamente, 1026 ha de lavouras produtivas, 310,7 ha de campo nativo, 458,5 ha de pastagens e 646,06 ha de vegetação florestal nativa, além de áreas de moradia da população rural, estradas e inúmeros animais mortos.

Para MULLER (1996), a nova linha de costa que surge com a formação de um reservatório é estabelecida em uma superfície geológica e biologicamente não preparada para a situação. A estrutura do solo, a vegetação que o cobre e a fauna que vive naquele lugar não estão justados às áreas ribeirinhas e zonas inundáveis temporariamente, como ocorre nos igarapés e várzeas marginais.

Observa-se também, que as áreas de mata nativa que restaram no entorno após o alagamento, começaram a exercer a função de APP, com isso, muitas espécies nativas que naturalmente não ocupavam as áreas ciliares, acabaram não conseguindo se adaptar às novas condições ambientais, e muitos indivíduos acabaram morrendo, e/ou reduzindo suas populações, pois não resistem à nova realidade, descaracterizando assim os poucos fragmentos que ainda permaneceram.

Segundo BATISTA et al. (2012) a construção de barragens altera a dinâmica natural, ocasionando sérios problemas que não se restringem apenas as áreas do reservatório. Estes problemas vão além, causando muitas vezes impactos sociais e ambientais, tanto nas áreas afetadas pelo alagamento, quanto nas áreas utilizadas para plantações e criações de rebanhos. Já COELHO (2008) em sua pesquisa diz que a fase de operação de uma usina hidrelétrica é aquela na qual o reservatório já está formado, estabelecendo uma nova paisagem local e as pessoas residentes no entorno têm que se adaptar a este novo cenário, que passa a ser parte integrante de suas vidas.

Além disso, a construção de hidrelétricas, acarretam em mudanças no microclima local, o que afeta a fauna e flora que restaram, além de, provocar um desequilíbrio e/ou extinção dos mesmos. BATISTA et al. (2012), refere-se ao aumento dos efeitos de borda devido à maior exposição de suas áreas aos efeitos bióticos e abióticos, que tem como consequência a alteração do ambiente, sejam elas microambientes, das condições microclimáticas e o deslocamento da fauna.

Estudos feitos no local por THOMAS \& BASSO (2013), indicam que além dos danos ocorrido na paisagem, ocorre a questão que no período chuvoso em muitos locais a água do lago sobe além do limite estimado, trazendo lama e lixo para as áreas que não possuem vegetação ciliar, como relatado por moradores em entrevistas realizadas com as famílias que residem perto da barragem.

Por meio de entrevistas feitas pelos mesmos autores, ficou evidente que para grande parte dos atingidos os benefícios foram poucos. $O$ alagamento passa do limite da APP, fato que ocorre principalmente quando chove em que o lago enche e passa do APP permitido. Trazendo inúmeras desvantagens para esses produtores, pois afeta diretamente a produção de gado, levando em conta que a pastagem não se recupera facilmente depois que a água baixa. Além de outros problemas, como 
lixo, a lama que se acumula e consequentemente impede os animais de beberem água do rio e o mau cheiro do local.

Dessa forma, elaborou-se também, um mapa que ilustra simultaneamente o formato do leito do rio ljuí com suas respectivas APP no ano de 2005, e no ano de 2014 posteriormente a construção da usina (Figura 4). Podemos visualizar de maneira mais lúdica o antes e depois e, quanto a paisagem do local foi impactada com a construção da UHE São José.

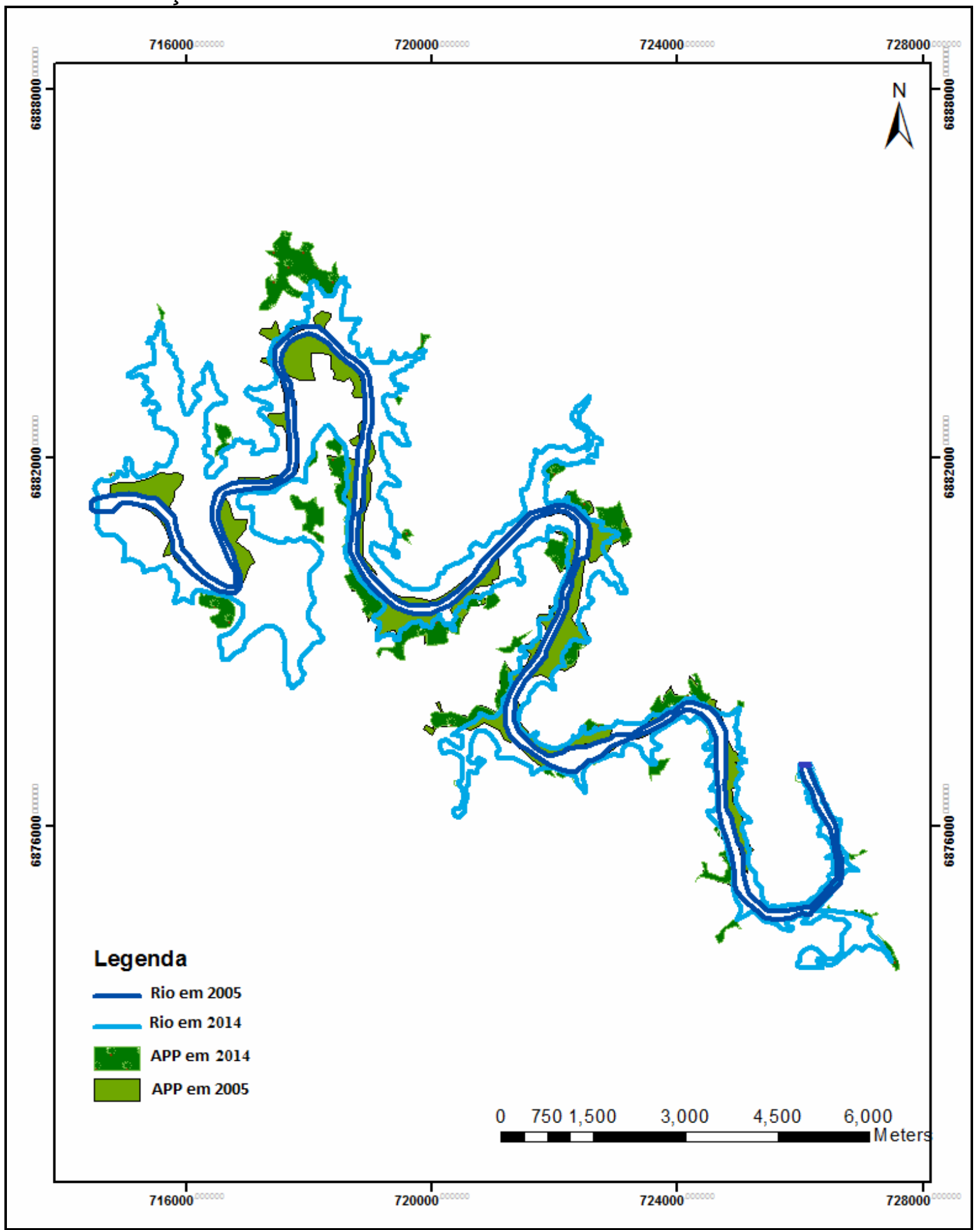

FIGURA 4: Mapa temporal com a sobreposição da área do leito do rio ljuí e APP em 2005 e área do lago com as APP em 2014. Fonte: Autores. 
Podemos notar também, que mais de $60 \%$ das margens do lago no ano de 2014 , está sem vegetação ciliar, o que proporciona maior erosão do solo, pois não existe nenhuma barreira que impeça o transporte de sedimentos, tornando as águas do reservatório mais turvas além do maior acúmulo de sedimentos. Diante do exposto, elaborou-se também, o mapa temporal dos anos de 2005 e 2014, somente com as APP existente e que atualmente estão exercendo esta função, para servir de suporte para o estudo e mensurar o impacto que as áreas ciliares do local sofreram. Como poder ser observado na Figura 5, restaram apenas 156,7 ha de área ciliar após a inundação do lago, visto que a área existente anteriormente chegava a entorno de 646,06 ha de APP. Essas informações constituem importante subsídio para a mensuração do impacto que as áreas ciliares do local sofreram com a instalação da hidrelétrica.

Conhecendo a estrutura atual das áreas ciliares, estudos ambientais e futuros planos de restauração ambiental devem ser planejados, de forma a implementar ações que auxiliem a reconstituição do ambiente perturbado.

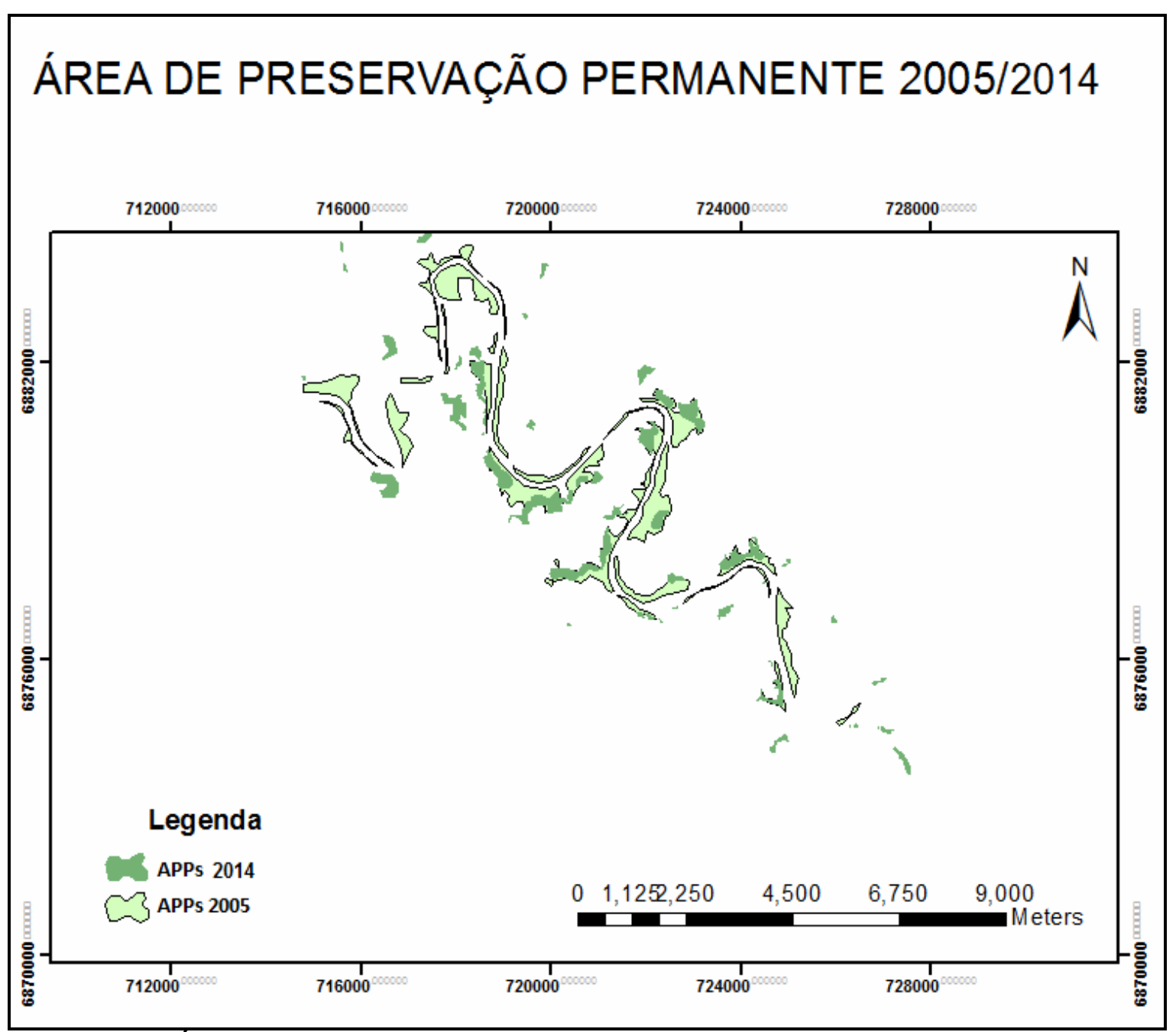

FIGURA 5: Áreas de mata ciliar no ano de 2005 e 2014. Fonte: Autores.

A revegetação das áreas de APP às margens dos reservatórios das usinas deve ser uma preocupação das empresas ligadas ao setor de geração de energia, como forma de minimizar a erosão e os impactos ambientais causados pela criação ENCICLOPÉDIA BIOSFERA, Centro Científico Conhecer - Goiânia, v.11 n.22; p.2263 
dos reservatórios, como a submersão de matas nativas. Visto que, as APP's são fundamentais contra a erosão do solo e o transporte de sedimentos, além de abrigar a fauna e proporcionar o equilíbrio do ecossistema local, isto em áreas de alagues, no entorno de reservatórios, bem como, em qualquer curso d'água,

Estudos realizados por GAVILANES \& BRANDÃO (1991), no município de Lavras - MG, demonstraram que a cobertura vegetal original, encontrava-se extremamente devastada; das formações florestais só restavam capões esparsos na cumieira das elevações, além de estreitas e fragmentadas matas ciliares ao longo dos cursos d'água. O que demonstra a falta de procedimentos visando a reestruturação das áreas ciliares em construções de usinas hidrelétricas pelo país.

Uma das possibilidades de amenizar o impacto ambiental e ecológico nos ecossistemas do local, é a criação de corredores ecológicos. Segundo COELHO (2008), deve-se observar alguns aspectos para a criação desses corredores, como o poder de resiliência do local, o grau de conservação dos fragmentos que restaram, a distância entre os mesmos, para que eles se tornem eficientes para o fluxo gênico entre as populações vegetais e animais.

O mesmo autor argumenta que a reestruturação das matas ciliares no entorno dos reservatórias, são fundamentais para a manutenção da biodiversidade, pois os fragmentos que estão próximos, não conseguem assumir exclusivamente o papel de restauradores ambientais

O Ministério Público Federal solicitou, em julho de 2005, a complementação dos EIA/RIMA da UHE São José, com fins de garantir a participação efetiva do Instituto do Patrimônio Histórico e Artístico Nacional (IPHAN) e da Fundação Nacional do Índio (FUNAI) no processo e na elaboração de um estudo adequado para a recomposição da mata ciliar atingida, bem como o destino das famílias residentes nas regiões a serem alagadas. No caso do impacto relativo à redução nas áreas ocupadas pelas formações vegetais, foi proposto o projeto de resgate da flora na área inundada e o projeto de criação da APP, esse último, sem atingir seus objetivos até a presente data. O projeto de resgate da flora poderia ter influenciado a nova paisagem surgida com a formação do lago, fornecendo material para a produção de mudas a serem utilizadas em projetos de recuperação de áreas degradadas, enriquecimento das matas existentes fora da área de inundação e recomposição da cobertura vegetal da localidade.

Segundo o Código Florestal Brasileiro em vigor, Lei 12.651/2012 - Seção I., as áreas no entorno dos reservatórios d'água artificiais, decorrentes de barramento ou represamento de cursos d'água naturais, na faixa definida na licença ambiental do empreendimento, serão considerada APP (BRASIL, 2012). O Art. 5o, da mesma Lei, refere-se a implantação de reservatório d'água artificial destinado à geração de energia ou ao abastecimento público, são obrigatórias a aquisição, a desapropriação ou a instituição de servidão administrativa pelo empreendedor das APP criadas em seu entorno, conforme estabelecido no licenciamento ambiental, observando-se a faixa mínima de 30 (trinta) metros e máxima de 100 (cem) metros em área rural, e a faixa mínima de 15 (quinze) metros e máxima de 30 (trinta) metros em área urbana (BRASIL, 2012).

Visto a proporção do impacto que a paisagem do local sofreu pela construção da usina e pela questão de atender a legislação vigente ao Código Florestal Brasileiro, em relação as Áreas de Preservação Permanente, e as funções que elas exercem no meio ambiente como um todo, elaborou-se um mapa, no qual, atribuiuse um valor de 50 metros a partir da margem do reservatório para a destinação de 
APP, visto o porte e as dimensões do lago, e também considerando que $100 \%$ do seu entorno se tratar de áreas no meio rural (Figura 6). Tendo como objetivo de recompor os danos que a paisagem e o ecossistema do local sofreram com a construção da usina, além de, evitar mais impactos às áreas e aos moradores no entorno.

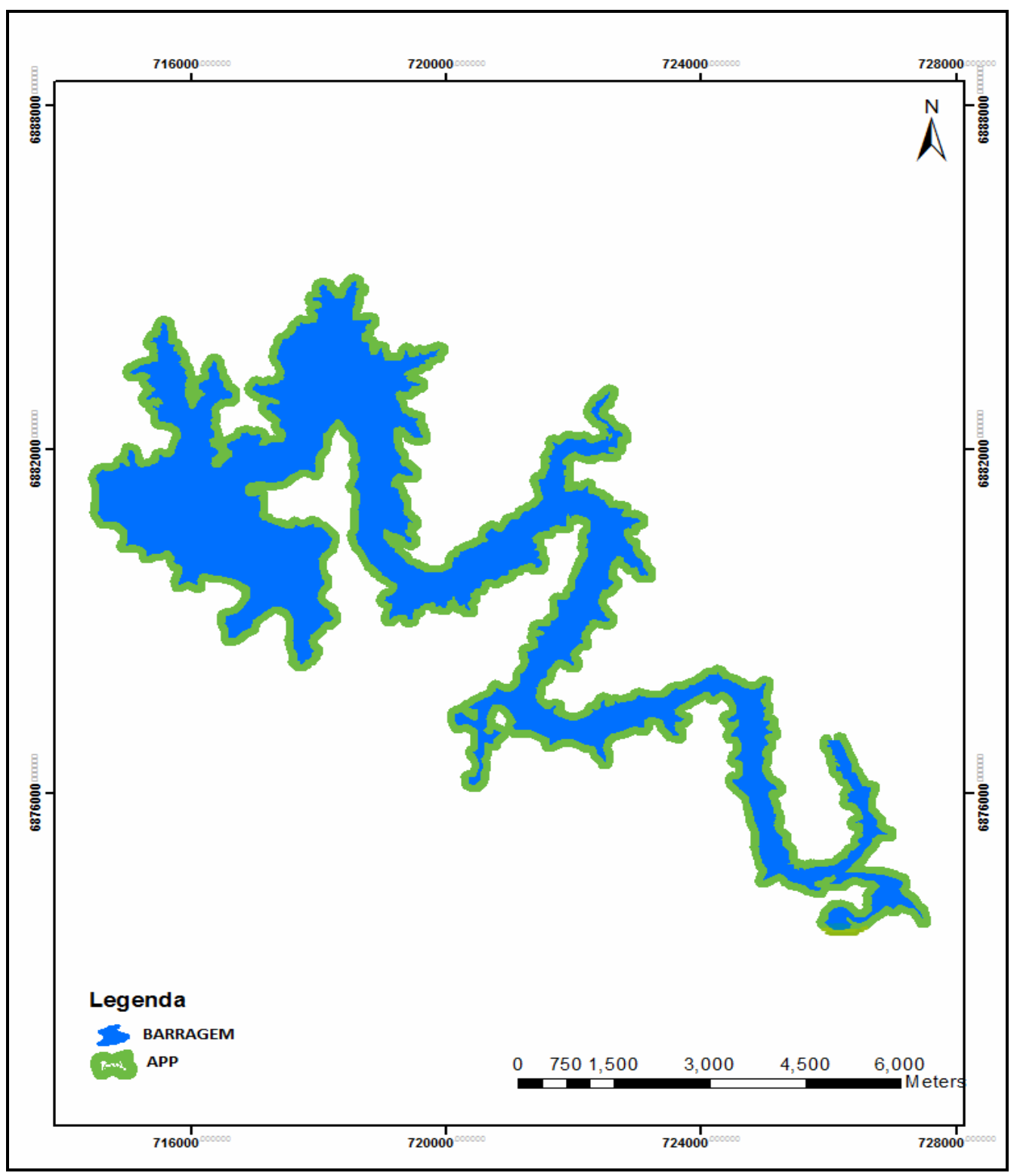

FIGURA 6: Mapa de restruturação da área de APP. Fonte: Autores.

Foi possível também, mensurar a área ocupada pela recomposição do mapa citado anteriormente, chegando a 401,67 ha, sendo 156,7 ha de mata nativa já existente no entorno do lago. Dessa forma, 245 ha ao longo das margens do reservatório deverão ser destinadas à APP.

Contudo, empreendimentos de grande impacto ambiental, como no caso da UHE São José, a análise das modificações da paisagem, contribuem para estudos tanto do âmbito ambiental, como social, pois a paisagem atua como elemento integrador dessas duas esferas, possibilitando pesquisas relacionadas a 
sustentabilidade ambiental e social das áreas atingidas e das comunidades no entorno.

\section{CONCLUSÃO}

Com base nas informações levantadas pela análise temporal proporcionadas por este estudo, foi possível visualizar o impacto ambiental causado à paisagem no local, após a conclusão das obras da UHE São José. Além de quantificar as áreas de mata ciliar suprimidas e destinadas ao lago da barragem, bem como a elaboração de um novo mapa para a recomposição das APP no entorno do lago de acordo com o Código Florestal Brasileiro vigente, com vista a amenizar o impacto causado a paisagem e a comunidade do entorno.

\section{REFERÊNCIAS}

ALVARES, C. A.; STAPE, J. L.; SENTELHAS, P. C.; GONÇALVES, J. L. M.; SPAROVEK, G. Köppen's climate classification map for Brazil. Meteorologische Zeitschrift, Stuttgart, v. 22, n. 6, p. 711-728, 2013.

BATISTA, B. M.; SÁNCHEZ, D. C. M.; SILVA, J. V. da; MARTINEZ, D. T.; PASA, M. C. Revisão dos Impactos ambientais gerados na fase de instalação das hidrelétricas: Uma análise do Alto Juruena - MT. Biodiversidade. V. 11, n¹, p 70-85, 2012.

BRASIL. Lei n. 6.938, de 31 de agosto de 1981. Dispõe sobre a Política Nacional do Meio Ambiente, seus fins e mecanismos de formulação e aplicação, e dá outras providências. Art. $6^{\circ}$ I, II. Órgão consultivo e del iberativo: o Conselho Nacional do Meio Ambiente (CONAMA). 31 de agosto de 1981. Disponível em: <http://www.planalto.gov.br/ccivil_03/leis/l6938.htm>. Acesso em: 01/06/15.

BRASIL. Lei n. 12.651, de 25 maio de 2012, institui nova lei florestal no Brasil. Modificada por Medida Provisória em outubro de 2012, pela Lei 12.727. Diário Oficial da República do Brasil. 12 de outubro de 2012. Disponível em:http://www.imaflora.org/downloads/biblioteca/52d7c3a819c3e_Guia_Aplicao_Nov a_Lei_Florestal.pdf. Acesso em: 20/04/2015.

COELHO, S. J. Transformações na paisagem decorrentes da construção de Usina Hidrelétrica do Funil - UHE-Funil e o impacto no município de ljaci, MG. Tese (Doutorado) - Universidade Federal de Lavras, 2008. Lavras: UFLA, 2008.

CONAMA - CONSELHO NACIONAL DO MEIO AMBIENTE. Resolução n. 001-86, de 23 de janeiro de 1986. No uso das atribuições que lhe confere o inciso II do artigo $7^{\circ}$ do Decreto $n^{\circ}$ 88.351, de $1^{\circ}$ de junho de 1983 , alterado pelo Decreto $n^{\circ}$ 91.305, de 3 de junho de 1985. De 23 de janeiro de 1986. Disponível em: < http://www.mma.gov.br/port/conama/res/res86/res0186.html>. Acesso: 02/06/15.

GALVILANES, M. L.; BRANDÃO, M. Informações preliminares acerca da cobertura vegetal do município de Lavras, MG. Daphane, Belo Horizonte, v.1, n.2, p.44-50, 1991. 
HINKEL, R. Vegetação ripária: funções e ecologia. In: SIMINÁRIOS DE HIDROLOGIA FLORESTAL: ZONAS RIPÁRIAS, 1., 2003, Alfredo Wagner. Anais ... UFSC, p. 40-48, 2003.

IBGE - INSTITUTO BRASILEIRO DE GEOGRAFIA E ESTATÍSTICA. Manual técnico da vegetação brasileira. Rio de Janeiro, RJ - Brasil, 2012. Disponível em:<ftp://geoftp.ibge.gov.br/documentos/recursos_naturais/manuais_tecnicos/manua I_tecnico_vegetacao_brasileira.pdf>. Acesso em: 25/07/15.

INSTITUTO BRASILEIRO DE GEOGRAFIA E ESTATÍSTICA - IBGE. Senso Municipais, Rio Grande do Sul. Brasília: IBGE/MMA, 2010.

INATOMI, T. A. H.; UDAETA, M. E. M. Análise dos Impactos Ambientais na Produção de Energia Dentro do Planejamento Integrado de Recursos. Secção de estudos estratégicos de energia e de desenvolvimento sustentável do GEPEA/EPUSP, p. 14, 2011.

MMA - Ministério do Meio Ambiente. Caderno setorial de recursos hídricos: geração de energia hidrelétrica / Ministério do Meio Ambiente, Secretaria de Recursos Hídricos. - Brasília: MMA, p. 112, 2006.

MULLER, A. C. Hidrelétricas, meio ambiente e desenvolvimento. São Paulo: Makron Books do Brasil, 1996.

RODRIGUES, M. T.; CERIGNONE, F. J.; RODRIGUES, B. T.; MALHEIROS, J. M.; MONTE, B. E. O.: CARDOSO, L. G. Utilização do geoprocessamento na classificação do uso da terra em áreas conflitantes da bacia hidrográfica do rio capivara no município de botucatu-sp. IV Workshop Internacional de Planejamento em Bacias Hidrográficas. 2013, Presidente Prudente. Anais... Presidente Prudente, SP: UNESP/FCT, 2013.

SALAMENE, S.; FRANCELINO, M. R.; VALCARCEL, R.; LANI, J. L.; SÁ, M. M. F.; Estratificação e Caracterização Ambiental da Área de Preservação Permanente do Rio Guandu/RJ. Revista Árvore, Viçosa-MG, v.35, n.2, p.221-231, 2011.

SOUSA, W. L. de. Impacto Ambiental de Hidrelétricas: Uma Análise Comparativa de Duas Abordagens, 2000. 160f. Dissertação (Mestre em Ciência em Planejamento Energético) - Pós-Graduação em Engenharia da Universidade Federal do Rio d Janeiro, 2000.

THOMAS, J. M.; BASSO, L. D. Interferência da barragem São José na comunidade da Vila Tremônia, em Cerro Largo (RS). In. Aportes do V Simpósio Iberoamericano em Comércio Internacional, Desenvolvimento e Integração Regional/ Antonio Roberto Lausmann Ternes (Org.), Márcia Adriana Dias Kraemer (Org.). - Santa Rosa: FEMA, 2013. Anais...FEMA, p. 1-7, 2013.

XAVIER, J. S.; ZAIDAN, R. T. (Org.) Geoprocessamento e Meio Ambiente. Rio de Janeiro. Ed. Bertrand Brasil. 328 p. 2011. 